\title{
Perceptions of Students on Environmental Impacts of Online Shopping: A Preliminary Study at a Public Malaysian University
}

\author{
Kai Wen Yong and Leong Wan Vun
}

\section{ABSTRACT}

The environmental impacts of online shopping are multifaceted as many factors are contributing to the impacts. This study was conducted to determine a public university undergraduate students' perceptions of the environmental impacts of online shopping and their intentions to reduce the impacts by using a questionnaire survey. One hundred twenty-six respondents were engaged through convenient sampling in this study. Results found that the majority of respondents perceived online shopping as environmentally friendly. They perceived that it does not contribute to climate change and will not be a major environmental risk in the future. Type of packaging (77.8\%), transport mode of freight $\mathbf{( 7 1 . 5 \% )}$ and amount of packaging $(69.9 \%)$ were the top three factors perceived to contribute to environmental impacts. However, a small number of the respondents perceived ICT equipment (32.5\%), express delivery $(28.5 \%)$ and time spent in searching online products $(\mathbf{2 4 . 6 \%})$ were the factors that contribute to environmental impacts. The majority of respondents $(\mathbf{7 4 . 6 \% )}$ perceived that packaging waste generation was the major environmental impact of online shopping. In contrast, carbon footprint, energy consumption and greenhouse gas emission made up of $56.4 \%, 53.3 \%$ and $44.4 \%$ of the total respondents. Most of the respondents intended to plan first before making any purchase to prevent wastage, reuse the packaging material and maximise the number of items of each purchase to reduce the environmental impacts. This preliminary study can provide the necessary background information on the level of awareness of university undergraduate students on this issue for future environmental education programs on online shopping.

Keywords: Environmental Impacts, Online Shopping, Perceptions, Sustainability.

\section{INTRODUCTION}

Internet shopping has seen massive growth in recent years with the rapid growth of internet technology and the widespread internet access by people [1]. This can be seen where the global sales of internet shopping in 2014 reached about $\$ 750$ billion, increasing $20 \%$ annually, as reported in Prologis. It is estimated that there were about 1.61 billion of people in the world who shop online and this accounted for $12.1 \%$ of sales in the Asia Pacific for 2016 [2]. As of June 2017 , the top 3 electronic commerce (e-commerce) sites in Malaysia 2017 are Lazada Malaysia, 11 street Malaysia, and Lelong.my with similar web monthly traffic estimates of 30,300,000, 10,200,000 6,200,000 respectively [3].

Many factors contributed to internet shopping. Customer repurchase intention shows that internet shopping has become the favourite option due to lower prices of goods, variety of online stores provided by shopping websites, without time and space limit, excellent customer service by online retailers
Published Online: November 11, 2021

ISSN: $2684-446 \mathrm{X}$

DOI :10.24018/ejgeo.2021.2.6.194

\section{K. W. Yong}

Faculty of Science and Natural Resources, Universiti Malaysia Sabah, Malaysia.

(e-mail: y.kwen@yahoo.com)

L.W. Vun*

Faculty of Science and Natural Resources, Universiti Malaysia Sabah, Malaysia.

(e-mail: bvun@ums.edu.my)

*Corresponding Author and a vast selection of merchandise [4]. The Internet User Survey found that eight out of ten online shoppers rated highly on e-commerce as they enjoyed the delightful experiences [5].

Several factors determine the environmental impacts of online shopping, such as passenger transport to collect the goods, volume of purchase for each delivery, amount and type of packaging materials, and freight transport [6]-[8]. Under specific circumstances, online shopping may be associated with environmental benefits such as emission saving from vehicles to shopping malls, reduction of retail space, inventories and waste. In the case of books, Matthews et al. claimed that e-commerce could help to reduce inventories if compared to conventional retailing and hence environmental saving by preventing book warehousing [9]. Although online shopping is assumed to replace in-store shopping trips completely, it is less likely to happen [10]. This is because consumer's trips may arise to return the unwanted goods, pick up the failed deliveries or substitute the 
former shopping trips with other journeys, which might ultimately contribute to climate change [8].

Internet shopping may impact the environment under certain circumstances, such as the emission of carbon dioxide [7]. Airfreight applied for shipping some of the online products tends to have higher emissions. For packaging, the product is likely to be packaged individually and the packaging may not be reused as online shopping uses corrugated boxes, bubble bags, polystyrene and plastic bags which take longer time to degrade [9]. Zhang et al. stated that most of them eventually will end up in the garbage dump if only a small amount of this packaging material was reused or recycled [11]. Another study concluded that online retailing might not be environmentally friendlier than traditional shopping [12]. In terms of purchase volume, it is environmental beneficial if the number of items purchased for each delivery is more because the environmental footprint per item varies inversely with the number of items for each delivery [8].

Perception is the way how an individual observes, understands, interprets and evaluates a referent object, action, experience, individual, policy or outcome [13]. The word "perceptions" is often used in environmental management and conservation studies. According to Bennett, research regarding perceptions is crucial as it can inform courses of action for improvement in conservation and governance, ranging from individual initiatives to international policies [13]. The environmental perception was found to affect the willingness of individuals in practices toward environment protection [14].

A study conducted by Tiwari and Singh found that the respondents who are well aware of e-commerce do not have a clear idea of the relationship between e-commerce and global warming [15]. Also, the respondents were unsure whether e-commerce has potentially positive environmental impacts much more than potentially negative impacts or vice versa. College students are considered an important market segment since internet shopping is gradually becoming more and more popular among them [16].

There have been limited studies on the perception of the environmental impacts of online shopping. Thus, this study investigates a local public university students' perception of this issue to fill in the research gap and provide information to the relevant stakeholders to ensure that online shopping is more environmentally sustainable.

\section{Methodology}

\section{A. Questionnaire and Sample Size}

A total of 126 respondents were engaged in this study and the sample size was within $95 \%$ confidence level and $10 \%$ of margin error of the total student population of the public university.

A questionnaire was divided into 4 parts: Part A, Part B and Part C. Part A is on demographics of respondents. Part B consists of questions regarding online shopping patterns that are made up of nine questions. Some of the questions can reveal the respondents' environmental behaviour in transport, shopping and waste management. Part C consists of 27 questions regarding respondents' perceptions on the environmental impacts of online shopping. In Part C, a fivepoint Likert scale ranging from 1 (strongly disagree) to 5 (strongly agree) was used. A pilot study was carried out to determine the validity and reliability of the questionnaire.

\section{B. Sampling and Data Analysis}

A total of 130 questionnaires were distributed and 126 usable questionnaires were retrieved which represented a return rate of $97 \%$. The respondents were selected by using the convenience sampling method whereby the undergraduate students who were willing to participate in the survey were selected as respondents. Besides that, the respondents selected were asked beforehand to ensure they have shopped online at least once as the prerequisite.

The questionnaires were administered face to face. In this process, the explanation on this study was given to the respondents before and during the filling up process to ensure that the respondents clearly understood the questions in order to get a more accurate answer from them. This approach also helps to ensure that the respondents answered all the questions. The data collection was conducted between the period of February to March 2018.

The data collected from all the respondents were analysed using descriptive statistics.

\section{RESUlts AND DiscUSSIONS}

\section{A. Demographics of the Respondents}

The respondents for this study were made up of 91 female $(72 \%)$ and 35 male respondents $(28 \%)$. This is nearly corresponding with the male to female student ratio of the undergraduate student population in the public university. The proportion of female to male undergraduate student population in 2018 was at $69 \%$ and $31 \%$, respectively. The respondents were also from the seven faculties in the university.

On the experience, 19 students had less than one year, whereas those with one year's experience made up 21 respondents. Most of the respondents in this study had the experience of online shopping of two years and above, which made up of 27 respondents, followed by those with three years made up of 26 respondents corresponding to $21 \%$ of total respondents. Nineteen respondents had four years and above of online shopping experience. In general, all the respondents had carried out online purchases before.

For the following results and discussion, references will be made to the 26 statements in the questionnaire as shown in the appendix. They are numbered as item 15 to 40 in the actual questionnaire. Not all the results to these statements are presented in this paper, only selected key findings are discussed.

\section{B. Pattern of Online Shopping}

Figure 1 shows the types of goods bought by respondents. This study found that most of the respondents bought clothing and footwear, which made up $30 \%$ of the purchases, followed by bags and handbags that made up of 58 respondents. 46 respondents bought electronic products online. Products on health and beauty, books, music, video games and sport equipment category were recorded with 36, 29 and 25 respondents, respectively. There were 13 respondents who 
bought home products and another 14 respondents had made purchases of jewellery and watch online. Diverse types of goods were bought through online shopping.

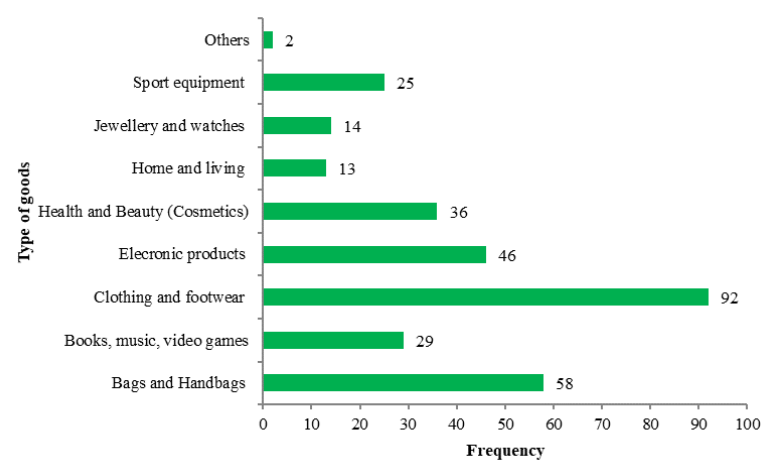

Fig. 1. Types of goods shopped online by respondents.

Fig. 2 shows the frequency of online shopping by respondents. Most of the respondents (23 respondents) had shopped online once in a year. Those who shop online once a month made up 21 respondents, which is equivalent to $13.6 \%$. Seven respondents did online shopping three times a month which was more frequent than other respondents. Approximately $36 \%$ of the respondents made monthly purchases.

Interestingly, when asked about whether online shopping can help to reduce the frequency of in-store shopping. About 89 respondents $(71 \%)$ stated that online shopping could reduce their in-store shopping frequency, whereas 37 respondents $(29 \%)$ stated that it did not reduce or replace instore shopping. This clearly shows that the substitution effect dominated the complementary effect. This indicated that online shopping had replaced some of the in-store shopping.

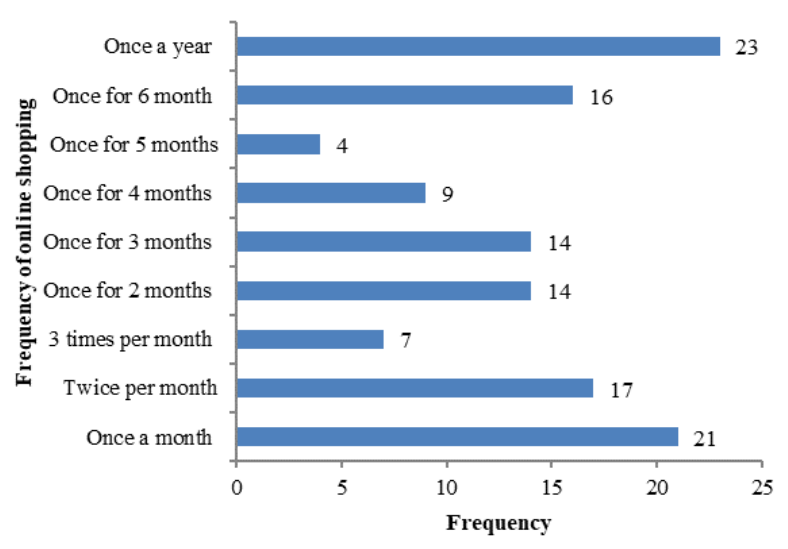

Fig. 2. Frequency of online shopping.

When asked about how the respondents dealt with the parcel's packaging, 105 respondents $(83 \%)$ stated that they threw away the packaging after opening the package (Fig. 3). Most of the packaging materials end up in garbage dumps as a very small amount of them are being reused or recycled, which may lead to soil contamination [11]. Only a minority of the respondents $(4 \%)$ recycled the packaging material. This probably was because not all packaging materials can be recycled, for instance, plastic bags, bubble bags, and polystyrene. According to McCarty and Shrum, more individuals perceived that recycling was inconvenient and were less likely to recycle [17]. $13 \%$ of the total respondents stated that they reused the packaging material including corrugated boxes. The respondents reused boxes, bubble bags and plastic bags for storage purposes. Some of them claimed that they would not simply throw away the packaging material and would reuse the plastic bag as garbage bags.

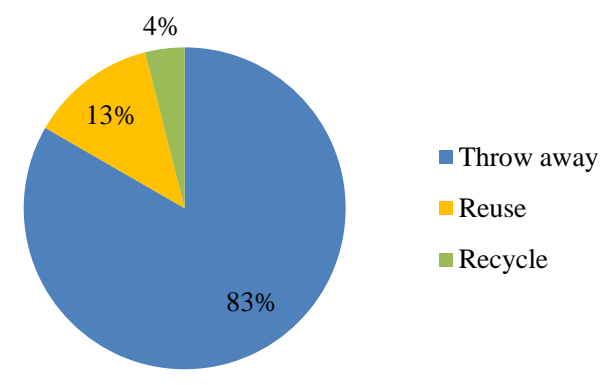

Fig. 3. Responses given regarding the management of the packaging of the parcel after the parcel is opened.

\section{Perception of Environmental Impacts of Online Shopping}

Fig. 4 shows the responses towards five statements (Q15Q19) in the questionnaire regarding early perception of the students on the issue of environmental impacts of online shopping. For the statement "online shopping is environmentally friendly", there were only two respondents strongly disagreed with this statement (1.6\%), both respondents are from the international tropical forest academic program, whereas there were about six respondents $(4.8 \%)$ who disagreed with this statement. Their choice of answers could be affected by their exposure to the forestry program [18]. Majority of the respondents agreed with this statement $(51.6 \%)$. There were 20 respondents $(15.9 \%)$ who strongly agreed with this statement. The number of respondents who agreed with this statement is much higher than those who disagreed, probably because they perceived online shopping could reduce the inventories, waste and emissions from delivery [19]. However, 26.2\% of the respondents did not hold any opinion for this statement which might indicate that they were unclear.

Question 16 is regarding the perception towards the statement "positive environmental impacts of online shopping are much more than negative impacts". About $11.1 \%$ and $48.4 \%$ of the total respondents strongly agreed and agreed to this statement, respectively. However, this result is different from the study conducted by Tiwari and Singh whereby most of the respondents were not sure whether the positive environmental impacts are much more than the negative impact [15]. There were three respondents $(2.4 \%)$ and 12 respondents $(9.5 \%)$ who chose "strongly disagree" and "disagree" respectively to this statement.

Fig. 4 also shows the perception of undergraduate students on question 17 which is regarding "online shopping has more negative environmental impacts". Most of the respondents disagreed with the statement which made up of 57 respondents (45.2\%). For those who strongly disagreed, they made up of 11 respondents $(8.7 \%)$. Forty respondents $(31.7 \%)$ chose neutral. 15 respondents $(11.9 \%)$ agreed and $2.4 \%$ (3 respondents) strongly agreed with this statement. 
Statement 18 on "online shopping increases climate change" clearly shows that most of the respondents did not agree with this statement whereby there were 40 respondents $(31.7 \%)$ who chose "strongly disagree" and "disagree" respectively. This could be due to the understanding that online shopping contributes to climate change indirectly whereby respondents could not relate online shopping with climate change. Only a minimal number of respondents agreed and strongly agreed with this statement which made up of 16 respondents $(12.7 \%)$ and 2 respondents (1.6\%) respectively.

For statement 19 regarding "online shopping will be a major risk to the environment in the future", it is found that there were 43 respondents $(34.1 \%)$ and 22 respondents $(17.5 \%)$ who chose "disagree" and "strongly disagree" with this statement respectively. For those who agreed and strongly agreed that online shopping will be a major risk to the environment in the future made up of 25 respondents $(19.8 \%)$ and 4 respondents $(3.2 \%)$ respectively.

Most respondents perceived that online shopping is environmental-friendly and is not responsible for climate change. Also, most of the respondents perceived that online shopping would not be a major risk to the environment. This is probably because they did not realise the online shopping activities potentially contribute to environmental impacts and climate change.

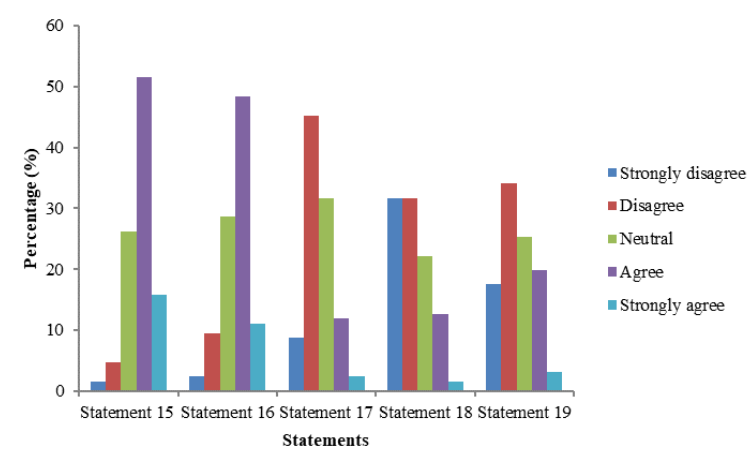

Fig. 4. Responses given towards the statements regarding the early perception of respondents: (S15) online shopping is environmentally friendly, (S16) positive environmental impacts of online shopping are much more than negative impacts and (S17) online shopping has more negative environmental impacts, (S18) online shopping increases climate change, (S19) online shopping will be a major risk to the environment in the future.

Fig. 5 summarises of perceptions towards the factors affecting the environmental impacts of online shopping. It clearly shows that type of packaging, transport mode of freight and amount of packaging were the top three factors perceived to contribute to the environmental impacts of online shopping as the majority of respondents agreed to this. On the other hand, express delivery, ICT equipment, and time spent searching for online goods were the top three perceived factors that would not impact the environment. One cannot simply conclude which factors contribute the most significant impact since the environmental impacts of online shopping are multifaceted because there are many factors involved in determining the effects on the environment [11]. Issue like multi-item orders could potentially be another concern.

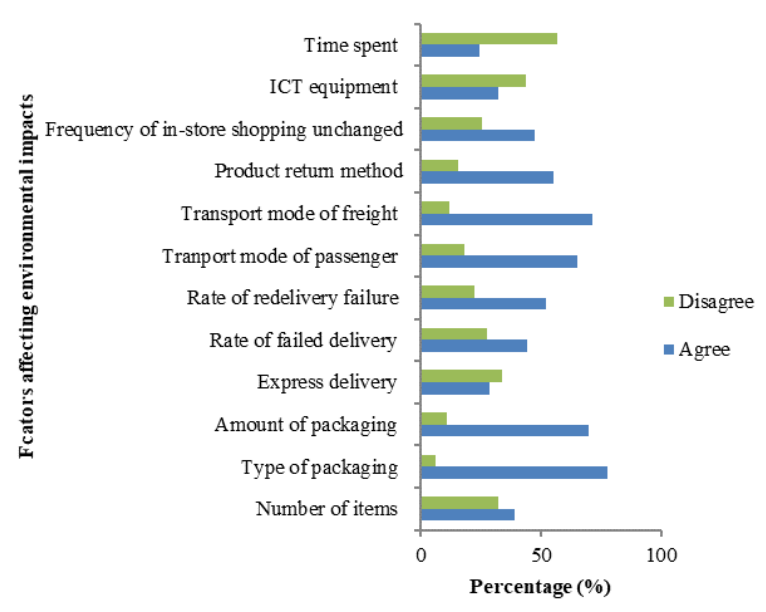

Fig. 5. Summary of perceptions towards the factors affecting the environmental impacts of online shopping.

Fig. 6 shows the perceptions of respondents towards statement 32 to statement 35 whereby these statements are related to the possible negative environmental impacts of online shopping. Statement 32 asked whether online shopping contributes to higher energy consumption. The lowest percentage among the five scales was neutral with 16 respondents $(12.7 \%)$. There were 17 respondents $(13.5 \%)$ strongly disagreed that online shopping consumes more energy. Those who chose "disagree" made up of 26 respondents, which is equivalent to $20.6 \%$. A study conducted on the users' perceptions of energy consumption in university buildings found that the awareness of energy usage was limited because of the university's lack of information and ownership in terms of energy consumption [20]. Students staying in university accommodation are not responsible for paying the electricity bills and probably this is one of the factors contributing to lack of ownership [20]. Forty-seven respondents $(37.3 \%)$ agreed that more energy will be used in online shopping. Only $15.9 \%$ of the total respondent strongly agreed with this statement.

Statement 33 asked whether respondents perceive packaging waste generation as one of the impacts of online shopping. A minority of them (3.2\%) strongly disagreed with this statement. Nine respondents $(7.1 \%)$ disagreed with this statement and $74.6 \%$ of the total respondents agreed or strongly agreed. This was probably due to the visibility of plastic bags and a huge number of bags littered [21]. These packaging wastes in landfills cause soil contamination, whereas incineration of the wastes will release dioxin, a persistent organic pollutant (POP) in the environment, potentially leading to air pollution.

The result towards the statement that online shopping contributes to carbon footprint is also shown in Fig. 6. Most respondents agreed with this statement whereby the highest percentage was recorded by those who agreed with this statement, 50 respondents $(39.7 \%)$. In contrast, those strongly agreed with this statement made up of 21 respondents $(16.7 \%)$. According to an unpublished study conducted by $\mathrm{Ng}$ on carbon footprint analysis of a public university undergraduate students' behaviour based on electricity use and transportation, most of the students did not have any knowledge about carbon footprint [22]. There were 5 
respondents $(4 \%)$ and 14 respondents $(11.1 \%)$ who chose "strongly disagree" and "disagree" respectively as their perception towards this statement.

$4.8 \%$ strongly disagreed with the statement which stated that online shopping contributes to greenhouse gas emission. Those who disagreed with this statement made up of 24 respondents (19\%) and 40 respondents $(31.7 \%)$ chose neutral as their perception towards this statement. However, most of the respondents agreed with the statement made up of 46 respondents $(36.5 \%)$ and 10 respondents $(7.9 \%)$ strongly agreed as shown in Fig. 6. Most of them agreed as such probably because online shopping is closely connected with express home deliveries and thus involves more freight vans in residential areas, which leads to the congestion issue and environmental concern [23].

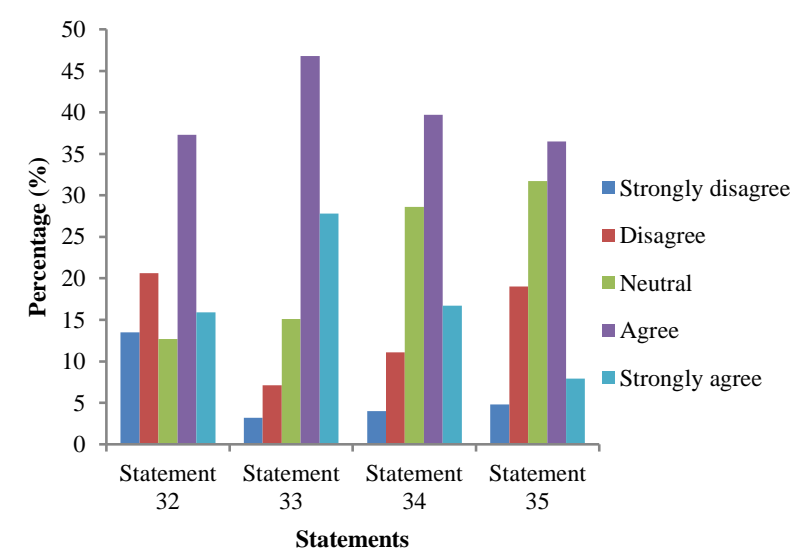

Fig. 6. Responses given towards statements regarding the environmental impacts of online shopping: (S32) more energy will be used for online shopping, (S33) packaging waste generation is one of the impacts of online shopping, (S34) online shopping contributes to carbon footprint, (S35) online shopping contributes to greenhouse gas emission.

Most of the respondents perceived packaging waste generation as the main issue of environmental impact from online shopping. This is probably due to the visibility of plastic bags and huge number of bags litter [21]. The number of perceptions for the other three impacts (Fig. 6, 33-45) namely energy consumption, carbon footprint and greenhouse gas emission, were much less compared to that of packaging waste generation probably these are perceived as indirect impacts from online shopping. To this matter, environmental education is necessary to educate the consumers on the differences of traditional and online shopping in terms of their attributes and environmental impacts [24], so that they can make a sensible decision in making purchases in the future.

\section{CONCLUSIONS}

This exploratory study found that most of the respondents perceived that online shopping is environmentally friendly and that online shopping is not responsible for climate change and will not be a major environmental risk in the future. The packaging type, mode of transport for freight and additional packaging were the top three factors perceived to contribute to the environmental impacts of online shopping. On the other hand, express delivery, utilisation of ICT equipment, and time spent searching for online goods were the top three factors perceived as causes no impact to the environment.

On another note, as online shopping is gaining popularity and might soon be something one cannot live without, thus there is a need to take this slowly. Many uncertainties might affect environmental sustainability because things are always not what they deem to be [25]. There is also a need to consider mutual sustainability and proper education for sustainable development to ensure that we do not head towards another "silent spring".

\section{APPENDIX}

Statements (15-40) on the perception on the issue of the environmental impact of online shopping.

15. Online shopping is environmentally friendly.

16. The positive environmental impacts of online shopping are much more than negative impacts.

17. Online shopping has more negative environmental impacts.

18. Online shopping increases climate change.

19. Online shopping will be a major risk to the environment in the future.

20. Number of item (s) for each purchase contributes to environmental impacts of online shopping.

21. Type of packaging used in online shopping contributes to environmental impacts of online shopping.

22. Amount of packaging used in online shopping contributes to environmental impacts of online shopping.

23. Express delivery contributes to environmental impacts of online shopping.

24. Rate of failed delivery contributes to environmental impacts of online shopping.

25. Rate of redelivery failure contributes to environmental impacts of online shopping.

26. Transport mode used by consumer to collect the goods at collection and delivery point (CDP) contributes to environmental impacts of online shopping.

27. Mode of transport used to send the products from the manufacturer to consumers contributes to environmental impacts of online shopping.

28. The product return method contributes to environmental impacts of online shopping.

29. Frequency of in-store shopping trip remains the same after shopping online contributes to environmental impacts of online shopping.

30. ICT equipment used for ordering and procession online orders contributes to environmental impacts of online shopping.

31. The time spent searching for online products will impact the environment.

32. More energy will be used for online shopping.

33. Packaging waste generation is one of the impacts of online shopping.

34. Online shopping contributes to carbon footprint.

35. Online shopping contributes to greenhouse gas emission.

36. It is possible to reduce the negative environmental impacts of online shopping.

37. Government should be responsible in reducing negative impacts of online shopping towards the environment.

38. Online retailer should be responsible in reducing negative impacts of online shopping towards the environment. 
39. Individuals should be responsible in reducing negative impacts of online shopping towards the environment.

40. No one should be responsible in reducing negative impacts of online shopping towards the environment.

\section{REFERENCES}

[1] D. Choudhury, and A. Dey, "Online shopping attitude among the youth: A study on university students," International Journal of Entrepreneurship and Development Studies, vol. 2, no. 1, pp. 23-32, 2014.

[2] Statista (October 2017). Online-shopping and E-commerce worldwide: Statistics and Facts. [Online] Available: https://www.statista.com/topics/871/online-shopping/.

[3] Asean Up. (October 2017) Top e-commerce sites in Malaysia 2017. [Online]7. Available: https://aseanup.com/top-e-commerce-sitesmalaysia/.

[4] C. Kim, R.D. Galliers, N. Shin, J.H. Ryoo, and J. Kim, "Factors influencing internet shopping value and customer repurchase intention," Electronic Commerce Research and Applications, vol. 11, pp. 374-387, 2012.

[5] MCMC (Malaysian Communications and Multimedia Commission) (October 2017). Internet User Survey 2016. [Online]. Available: http://www.mcmc.gov.my/skmmgovmy/media/General/pdf/IUS2016. pdf.

[6] C. Borggren, A. Moberg, and G. Finnvreden, "Books from an environmental perspective part 1: environmental impacts of paper books sold in traditional and internet bookshops," International Journal of Life Cycle Assessment, vol. 11, no. 2, pp.138-147, 2011.

[7] H. Pålsson, F. Pettersson, and L.W. Hiselius, "Energy consumption in e-commerce versus conventional trade channels - Insights into packaging, the last mile, unsold products and product returns," Journal of Cleaner Production, vol. 164, pp. 765-778, 2017.

[8] P. Van Loon, L. Deketele, J. Dewaele, A. McKinnon, and C. Rutherford, "A comparative analysis of carbon emissions from online retailing of fast-moving consumer goods," Journal of Cleaner Production, vol. 106, pp. 478-486, 2014.

[9] H.S. Matthews, C.T. Hendrickson, and D.L. Soh, "Environmental and economic effects of e-commerce: a case study of book publishing and retail logistics," Transportation Research Record, vol. 1763, no. 2, pp. 6-12, 2001.

[10] S. Farag, T. Schwanen, M. Dijst, and J. Faber, "Shopping online and/or in-store? A structural equation model of the relationships between eshopping and in-store shopping," Transportation Research Part A: Policy and Practice, vol. 41, no. 2, pp.125-141, 2007.

[11] M. Zhang, Y. Chen, and Y. Shen, "Environmental \& Analytical Toxicology China's environmental Threats of Internet Shopping Packaging Wastes," J Environ Anal Toxicol, vol. 6, no. 5, pp. 1-5, 2016.

[12] S. Cullinane, "From Bricks to Clicks: The impact of Online Retailing on Transport and the Environment," Transport Reviews, vol. 29, pp. 759-776, 2009.

[13] N.J. Bennett, "Using perceptions as evidence to improve conservation and environmental management: A review," Conservation Biology, vol. 30, no. 3, pp. 582-592, 2016

[14] K.M.L. Carman, and W.L.C. Eddie, "Green purchase behavior of undergraduate students in Hong Kong," The Social Science Journal, vol. 53, pp. 67-76, 2016.

[15] S. Tiwari, and P. Singh, "E-commerce: Prospect or threat for environment," International Journal of Environmental Science and Development, vol. 2, no. 3, pp. 211-217, 2011.

[16] P. Balaji, "Online shopping behaviour of college students," International Journal of Commerce and Business Management, vol. 8, no. 1, pp. 84-87, 2015.

[17] J.A. McCarty, and L.J. Shrum, "The recycling of solid wastes: Personal values, value orientations, and attitudes about recycling as antecedents of recycling behavior," Journal of Business Research, vol. 30, no. 1, pp. 53-62, 1994.

[18] R.E. Jackson, C.R. Willey, and L.K. Cormack, "Learning and Exposure Affect Environmental Perception Less than Evolutionary Navigation Costs," PLoS ONE, vol. 8, no. 4, pp. e59690, 2013.

[19] H.S. Matthews, E. Williams, T. Tagami, and C.T. Hendrickson, "Energy implications of online book retailing in the United States and Japan," Environmental Impact Assessment Review, vol. 22, no. 5, pp. 493-507, 2002.

[20] C.G. Whittle, and C.R. Jones, "User perceptions of energy consumption in university buildings: A University of Sheffield case study," Journal of Sustainability Education, vol. 5, May 2013.
[21] D. Starovoytova, "Consumer-perception on polyethylene-shoppingbags," Journal of Environment and Earth Science, vol. 6, no. 11, pp.1236, 2016.

[22] S.S. Ng, "Carbon footprint analysis of UMS undergraduate students' behavior based on electricity use and transportation," B.Sc. (Hons) thesis, Faculty of Science and Natural Resources, Universiti Malaysia Sabah, Malaysia, 2017.

[23] J. Francke, and J. Visser, "Internet shopping and its impacts on mobility," 25th World Road Congress (PIARC), 2-6 November 2015, Seoul. 2015.

[24] T. Chi, and Y.W. Zheng, "Understanding environmentally friendly apparel consumption: an empirical study of Chinese consumers," International Journal of Sustainable Society, vol. 8, no. 3, pp. 206-227, 2016.

[25] L.W. Vun, "Letter to the editor: 4Ss for sustainability," International Journal of Environmental Studies. DOI: 10.1080/00207233.2015.1031568, April 2015.

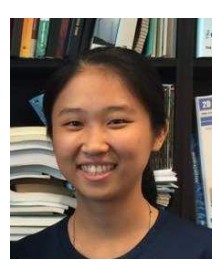

Kai Wen Yong holds a BSc (Hons) in Environmental Science from the Faculty of Science and Natural Resources, Universiti Malaysia Sabah. She is currently attached as an environmental officer to a plantation company based in Sabah.

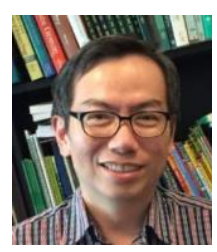

Leong Wan Vun is currently attached with Faculty of Science and Natural Resources as a researcher and lecturer in environmental management. He holds a $\mathrm{PhD}$ in environmental conservation and management. 